\title{
Em busca de repositórios digitais confiáveis no Brasil: análise da infraestrutura organizacional conforme a norma ISO 16363/2012
}

\author{
Searching trusted digital repositories in Brazil: analysis of the \\ organizational infrastructure according to ISO 16363/2012 standard \\ En la búsqueda de repositorios digitales confiables en Brasil: análisis de \\ la infraestructura organizacional bajo la normativa ISO 16363/2012
}

\author{
Laura Vilela Rodrigues Rezende | lauravil.rr@gmail.com \\ Universidade Federal de Goiás, Faculdade de Informação e Comunicação. Goiânia, Brasil. \\ Sonia Aguiar Cruz-Riascos | sonia.cruzriascos@gmail.com \\ Universidade Federal de Pernambuco, Departamento de Ciência da Informação. Recife, Brasil.
}

Daniela Francescutti Martins Hott | francescutti6g@gmail.com

Câmara dos Deputados. Brasília, Brasil.

\section{Resumo}

O início deste século marcou o cenário brasileiro por inúmeras iniciativas de implantação de repositórios digitais, as quais ocorrem até o presente momento, impulsionadas pela necessidade de se reunir em uma única solução de armazenamento a produção informacional relevante das instituições. Trata-se de um estudo analítico apresentando um panorama situacional como base no levantamento de indicações da infraestrutura organizacional de repositórios digitais em universidades públicas federais e instituições de pesquisa brasileiras considerando os parâmetros da norma ISO 16363/2012. Pesquisa descritiva, com abordagem quali-quantitativa. Apresenta indicadores observando os seguintes critérios: viabilidade organizacional e de governança, estrutura organizacional e de pessoal, estrutura de rotinas de procedimentos documentadas e política de preservação, sustentabilidade financeira, contratos, licenças e responsabilidades. Somente 17,6\% dos repositórios participantes iniciaram atividades avaliativas, ressaltando-se, contudo, que nenhum atua com certificação. Entende-se que há necessidade de instituir ações pautadas na norma ISO 16363 com vistas à tornar os repositórios brasileiros confiáveis.

Palavras-chave: Repositórios digitais confiáveis; Preservação digital; ISO 16363/2012; Academias e Institutos; Brasil. 


\begin{abstract}
Brazilian scenario at the beginning of this century was marked by implementation of several digital repositories and it is still occurring until this moment. It happens because of the need to gather in a single storage solution the relevant informational production of the institutions. This is an analytical study presenting a situational panorama of digital repositories in federal public universities and Brazilian research institutions through a survey about organizational infrastructure considering the parameters of ISO 16363/2012. It is a descriptive research with a qualitative and also a quantitative approach. The indicators presented observe the following criteria: organizational and managerial feasibility, organizational and personnel structure, documented procedures' routine and preservation policy, financial sustainability, contracts, licenses and responsibilities. Only $17.6 \%$ of the repositories started evaluative activities and none of them acts with certification. In conclusion, it is important that these institutions promote actions based on ISO 16363/2012 to make Brazilian repositories reliable.
\end{abstract}

Keywords: Trusted digital repositories; Digital preservation; ISO 16363/2012, Academies and Institutes; Brazil.

\title{
Resumen
}

El inicio de este siglo marcó el escenario brasileño con innumerables iniciativas de implantación de repositorios digitales, las cuales ocurren, hasta el momento, impulsadas por la necesidad de reunir en una única solución de almacenamiento de la producción informacional de las instituciones. Se trata de un estudio analítico presentando un panorama situacional. Como base del levantamiento se utilizaron indicadores de la infraestructura organizacional para análisis de los repositorios digitales en universidades públicas federales e instituciones de investigación brasileñas. Fueron considerados los parámetros de la norma ISO 16363/2011. Esta és una investigación descriptiva, con abordaje cualitativo y cuantitativo. Se presentan indicadores observando los siguientes criterios: viabilidad organizacional y de gobernanza, estructura organizacional y de personal, estructura de rutinas de procedimientos documentados y política de preservación, sostenibilidad financiera, contratos, licencias y responsabilidades. Sólo el 17,6\% de los repositorios participantes iniciaron actividades evaluativas, resaltando, que ninguno actúa con certificación. Se entiende que hay necesidad de instituir acciones pautadas en la norma ISO 16363/201? con miras a hacer que los repositorios brasileños sean de confianza.

Palabras clave: Repositórios digitales confiables; Preservación digital; ISO 16363/2012; Academias e Institutos; Brasil.

\section{Introdução}

A evolução da tecnologia da informação e a sua inserção na Ciência da Informação proporcionou rupturas na concepção e no desenvolvimento de repositórios digitais confiáveis. Entende-se como repositórios digitais (RDs) as bases de dados online que reúnem de maneira organizada a produção científica de uma instituição ou área temática; nele, encontram-se arquivos de diversos formatos, entretanto sua preservação é um capítulo à parte devido à complexidade da garantia da autenticidade, da confiabilidade e da permanência dos dados e informações. De tal modo, há necessidade de estudos aprofundados, definições conceituais, tecnologias e processos específicos para essa área por parte dos profissionais de informação. Em um mundo globalizado digital, os repositórios se configuram como uma boa alternativa para preservação, no entanto, que possa ser estabelecida ao longo prazo.

No Brasil, em geral, os repositórios ainda estão aquém do estágio de fornecimento de garantias satisfatórias para a preservação e acesso da memória científica brasileira, considerando, também, que há existência de normas, diretrizes e normativos em vigor que, todavia, não são aplicados ou de forma adequada ou de maneira segura.

Algumas publicações de autores como Crown ${ }^{1}$, Costa e Leite ${ }^{2}$, e Lynch ${ }^{3}$ se referem ao repositório digital das universidades, como Repositório Institucional (RI). Para o presente artigo, optou-se pela definição adotada pelo Conselho Nacional de Arquivos4, na qual "Repositório Digital" tem como definição básica 
a construção de parâmetros que visem conferir confiabilidade a esta ferramenta, e um repositório digital confiável é aquele capaz de manter autênticos os materiais digitais, de preservá-los e de prover acesso a eles pelo tempo necessário.

O Brasil foi marcado no início do século XXI por inúmeras iniciativas de implantação de repositórios digitais, impulsionadas pela necessidade de se reunir em uma única solução de armazenamento a produção informacional relevante de suas instituições. As iniciativas brasileiras de maior relevância no cenário dos repositórios digitais foram conduzidas pelo Instituto Brasileiro de Informação em Ciência e Tecnologia $(\text { IBICT) })^{5}$, promovendo ações de fomento ao acesso aberto no Brasil.

No país, iniciativas de implantação de repositórios digitais vêm sendo conduzidos isoladamente faltandolhes interlocução com alguma ação ao nível macro que lhes possa sugerir melhores práticas, recomendações de padrões e normas técnicas internacionais. Essa problemática gera uma lacuna, especialmente em se tratando de questões envolvidas com a preservação digital e a confiabilidade desses repositórios digitais.

O referencial normativo da Organização Internacional de Normalização ISO 16363:2012 ${ }^{6}$ - Audit and certification of trustworthy repositories tem sua origem baseada no Trustworthy Repositories Audit and Certification Checklist (TRAC), publicado em 2007, por dois grupos da área de Ciência da Informação, o Research Library Group (RLG) e o National Archives and Records Administration (NARA), ambos dos Estados Unidos. Sua proposta é oferecer e disponibilizar uma ferramenta na qual seja possível auditar, avaliar e certificar os repositórios digitais. Este instrumento normativo também estabelece não somente a documentação necessária que valida e certifica um repositório digital, mas também fornece diretrizes de como torná-lo um recurso sustentável.

Essa norma está dividida em cinco seções, sendo que as duas primeiras são informações gerais e as três ultimas propõem métricas nas áreas de Infraestrutura Organizacional, Gestão de Objetos Digitais, e Infraestrutura e Gestão de Segurança de Riscos. Diante do contexto narrado, esta pesquisa realizou estudo analítico com a proposta de apresentar um panorama situacional como base no levantamento de indicações da infraestrutura organizacional de repositórios digitais em universidades públicas federais e instituições de pesquisa brasileiras considerando os parâmetros da norma ISO 16363:2012.

\section{Estratégia metodológica}

$\mathrm{O}$ foco desta pesquisa descritiva com abordagem quanti-qualitativa foi fundamentada na aplicação de métricas inseridas na categoria de infraestrutura organizacional da ISO 16363/2012. O processo de avaliação objetivou determinar se os repositórios digitais da amostra eram confiáveis ou não sob a categoria supramencionada. A referida categoria é pautada em questões relacionadas à gestão, aos processos, às políticas e aos recursos humanos da instituição, considerando que a existência de um repositório precisa estar pautada na garantia de compromisso com a preservação, gestão e acesso aos dados que nele estão inseridos. Nesta investigação, foi elaborado um questionário, como instrumento de coleta de dados voltado exclusivamente para a dimensão da categoria supracitada.

Logo, o âmbito da análise envolve o contexto administrativo vinculado ao repositório, informações sobre a missão institucional e os aspectos contemplados na declaração da missão do repositório, com vistas à verificação se estes estão ou não relacionados à estrutura administrativa, como também, à medição do grau de participação e da interrelação do staff administrativo, - tanto da alta administração como da equipe diretamente envolvida nas atividades de preservação, gestão e acesso do repositório digital.

Para delimitação do universo, o critério estabelecido foi o de selecionar repositórios com mais de um mil registros (1.000) indexados no OPENDOAR7 , e obteve-se o quantitativo de quarenta e seis repositórios (46). Definiu-se a amostra de vinte e sete (27) instituições, com retorno de dezessete respondentes (63\%). 


\section{Resultados}

A pesquisa apresenta como resultados a análise situacional desses repositórios, observando, os indicadores pertinentes à categoria da infraestrutura organizacional, isto é, trazendo questões do escopo organizacional das instituições sob os seguintes critérios: viabilidade organizacional e de governança, estrutura organizacional e de pessoal, estrutura de rotinas de procedimentos documentadas e política de preservação, sustentabilidade financeira, contratos, licenças e responsabilidade. Logrou-se com a investigação conhecer o contexto desses repositórios digitais.

Com referência à amostra do estudo, tem-se a configuração descrita na tabela 1.

Tabela 1. Tipos de Repositório por Região Geográfica - 2016

\begin{tabular}{l|c|c|c|c|c}
\hline Repositórios / Regiões & Centro-Oeste & Norte & Nordeste & Sul & Sudeste \\
\hline Repositórios de Universidades & 02 & 01 & 04 & 04 & 02 \\
\hline Outros Repositórios & 03 & - & - & - & 01 \\
\hline
\end{tabular}

Segundo a dimensão organizacional da norma ISO 16363, entende-se que o repositório deve ter uma declaração de missão a qual reflita o comprometimento da organização com a preservação, custódia de longo prazo, gestão e acesso à sua informação digital. Pretende-se indicar definições, recomendações de padrões e normas técnicas, dentre outras questões envolvidas com a preservação digital e a confiabilidade dos repositórios. É possível observar que a maioria dos repositórios, perfazendo um total de treze (13) possuem declaração de missão, ou seja 76,5\%, e apenas quatro (04) ainda não a possuem (23,5\%).

Na pergunta seguinte, ainda relativa à missão, cabia ao respondente informar os aspectos abordados na mesma, como: preservação, custódia de longo prazo, gestão, acesso à informação e outros com o pedido de que informassem quais. Segue-se a tabela 2.

Tabela 2. Quantidade e tipos de aspectos na Declaração de Missão por Repositórios - 2016

\begin{tabular}{c|l|c|c}
\hline $\begin{array}{c}\text { Quantidade de } \\
\text { aspectos }\end{array}$ & Aspectos declarados na missão & $\begin{array}{c}\text { Repositórios de } \\
\text { Universidades }\end{array}$ & $\begin{array}{c}\text { Outros } \\
\text { repositórios }\end{array}$ \\
\hline 04 & $\begin{array}{l}\text { Preservação, Custódia de Longo } \\
\text { Prazo, Gestão, Acesso à Informação } \\
\text { Digital }\end{array}$ & 04 & 01 \\
\cline { 2 - 4 } & $\begin{array}{l}\text { Preservação, Gestão, Acesso à } \\
\text { Informação Digital e Opção Outros } \\
\text { (sem citar) }\end{array}$ & - & 01 \\
\hline \multirow{2}{*}{03} & $\begin{array}{l}\text { Preservação, Gestão e Acesso à } \\
\text { Informação Digital }\end{array}$ & 02 & 01 \\
\cline { 2 - 4 } & $\begin{array}{l}\text { Custódia de Longo Prazo, Gestão e } \\
\text { Acesso à Informação Digital }\end{array}$ & 01 & - \\
\hline 02 & Gestão e Acesso à Informação Digital & 01 & - \\
\hline 01 & Gestão & 01 & - \\
\cline { 2 - 4 } & Opção Outros (sem citar) & 01 & - \\
\hline
\end{tabular}

Como análise baseada nos resultados apresentados, destacam-se os aspectos mais considerados (gestão e acesso à informação digital), e de menor incidência (custódia de longo prazo). Aponta-se a urgência de as 
instituições observarem um dos principais propósitos da preservação digital que se traduz na garantia de acesso ao longo prazo de documentos digitais.

Quanto ao mapeamento das fases de implantação em que o repositório se encontra, e é interessante observar os dados na Tabela 3, a seguir. Ressanta-se que a maioria dos repositórios já se encontra com tais bases de dados implantadas de forma integral, treze (13) ou 76,5\%. Logo, pode-se dizer que a constatação apontada na Tabela 2 reforça a falta de diretrizes quanto à custódia de longo prazo.

Tabela 3. Fase em que se encontram os Repositórios - 2016

\begin{tabular}{l|c|c}
\hline Fase em que o repositório se encontra & $\begin{array}{c}\text { Repositórios de } \\
\text { Universidades }\end{array}$ & $\begin{array}{c}\text { Outros } \\
\text { repositórios }\end{array}$ \\
\hline Implantado integralmente (em fase de uso pleno) & 10 & 03 \\
\hline $\begin{array}{l}\text { Em fase final de implantação (em funcionamento porém ainda em } \\
\text { avaliação e recebendo correções) }\end{array}$ & 01 & - \\
\hline $\begin{array}{l}\text { Em fase avançada de implantação (mais de 50\% do processo do } \\
\text { povoamento já realizado) }\end{array}$ & - & 01 \\
\hline $\begin{array}{l}\text { Em fase intermediária (com política já existente e iniciando o } \\
\text { povoamento) }\end{array}$ & 01 & - \\
\hline $\begin{array}{l}\text { Em fase inicial de implantação (pós-planejamento, com instalação } \\
\text { recente) }\end{array}$ & - & - \\
\hline Outra fase. Indicar. & 01 & \\
\hline
\end{tabular}

Outro aspecto de análise tratou da existência de um plano ou documento relativo aos profissionais que lidam com os repositórios. A Tabela 4 apresenta os resultados.

Tabela 4. Conteúdo do Plano de Gestão de Pessoas nos Repositórios - 2016

\begin{tabular}{l|c|c}
\hline Indicação de plano / documento de pessoal & $\begin{array}{c}\text { Repositórios de } \\
\text { Universidades }\end{array}$ & $\begin{array}{c}\text { Outros } \\
\text { repositórios }\end{array}$ \\
\hline Os cargos, as funções e as responsabilidades da equipe & 04 & 02 \\
\hline $\begin{array}{l}\text { Detalhamento das competências para atuação profissional junto } \\
\text { ao repositório }\end{array}$ & 01 & - \\
\hline Orientações para alinhamento de competências requeridas & 01 & - \\
\hline Não existe plano de pessoal & 05 & - \\
\hline Outro. Indicar & - & - \\
\hline Outra fase. Indicar* & 02 & - \\
\hline
\end{tabular}

Tem-se, portanto, que a maior parte dos repositórios não possui plano ou documento relativo ao quadro de pessoal com regimento orientador a respeito da gestão de pessoas. Então, pode-se sinalizar que, as instituições detentoras dos repositórios, em geral tratam das questões de pessoal em seus respectivos departamentos de recursos humanos, sem vinculação direta e orgânica com as funções exercidas nos repositórios. Subentende-se ainda que os membros das equipes responsáveis pelos repositórios exercem outras funções na instituição. 
Entretanto equipes de dois (02) repositórios de universidades assinalaram a opção "Outros”, descreveram as seguintes indicações*: 1) Diretrizes de entrada de documentos, criação e gerenciamento das comunidades e coleções. Questão de direitos autorais e acesso aberto; e - 2) Dispomos de uma portaria nomeando dezessete (17) bibliotecários do Sistema Integrado de Bibliotecas (SIB), para as setoriais. No entanto, essa documentação específica do plano de pessoal está em fase de elaboração.

Ademais, sobre o mapeamento de competência e habilidades, os resultados apontam que apesar de a maior parte dos repositórios não apresentar plano de gestão de pessoas, tem-se equipes com adequação às tarefas desempenhadas para o repositório em dez (10) instituições $(58,8 \%$ ) e nos demais (07), a capacitação atende parcialmente com o esperado (41,2\%).

Pesquisas sobre repositórios no país tem indicado quantitativo de pessoal inferior ao adequado, e a presente coleta corrobora essa questão, apontando quadro enxuto ou déficit de profissionais, visto que em onze (11) repositórios, constam entre quatro (04) a cinco (05) servidores atuantes, conforme as Tabelas 5 e 6.

Tabela 5. Quantitativo de pessoal nos Repositórios - 2016

\begin{tabular}{c|c|c|c}
\hline $\begin{array}{c}\text { Quantitativo de pessoal } \\
\text { suficiente }\end{array}$ & Repositórios de Universidades & Outros repositórios & Percentual \\
\hline Sim & 04 & 02 & $35,3 \%$ \\
\hline Não & 09 & 02 & $64,7 \%$ \\
\hline
\end{tabular}

Tabela 6. Quantitativo detalhado de pessoal nos Repositórios - 2016

\begin{tabular}{|c|c|c|}
\hline $\begin{array}{l}\text { Quantitativo de } \\
\text { pessoal suficiente }\end{array}$ & Repositórios de universidades & Outros repositórios \\
\hline \multirow[t]{4}{*}{ Sim } & $\begin{array}{l}\text { Universidade A: } \\
16 \text { servidores / bolsistas, sendo } 09 \text { da equipe } \\
\text { gestora e } 7 \text { da equipe técnica. }\end{array}$ & \multirow[t]{2}{*}{$\begin{array}{l}\text { Repositório A: } \\
03 \text { servidores }\end{array}$} \\
\hline & $\begin{array}{l}\text { Universidade B: } \\
10 \text { servidores / bolsistas, sendo } 05 \text { da equipe } \\
\text { técnica e } 05 \text { da equipe de apoio. }\end{array}$ & \\
\hline & $\begin{array}{l}\text { Universidade C: } \\
20 \text { servidores / bolsistas }\end{array}$ & \multirow[t]{2}{*}{$\begin{array}{l}\text { Repositório B: } \\
03 \text { servidores }\end{array}$} \\
\hline & $\begin{array}{l}\text { Universidade D: } \\
05 \text { servidores / bolsistas }\end{array}$ & \\
\hline \multirow[t]{7}{*}{ Não } & $\begin{array}{l}\text { Universidade E: } \\
02 \text { servidores, mas o ideal seriam } 04\end{array}$ & \multirow{4}{*}{$\begin{array}{l}\text { Repositório C: } \\
03 \text { servidores, mas o idea } \\
\text { seriam } 05 \text { servidores }\end{array}$} \\
\hline & $\begin{array}{l}\text { Universidades F e G: } \\
02 \text { servidores, mas o ideal seriam } 05\end{array}$ & \\
\hline & Universidade $\mathrm{H}$ : o ideal seriam 20 & \\
\hline & Universidade I: 09 servidores em regime parcial & \\
\hline & Universidade J e K: o ideal seria ter pelo menos 04 & $\begin{array}{l}\text { Repositório D: } \\
03 \text { servidores, mas o ideal } \\
\text { seriam } 05 \text { servidores }\end{array}$ \\
\hline & Universidade L: não respondeu & \\
\hline & $\begin{array}{l}\text { Universidade M: } 12 \text { servidores, necessita de } \\
\text { equipe de TI, mas não especificou o quantitativo } \\
\text { ideal }\end{array}$ & \\
\hline
\end{tabular}


Os dados da Tabela 6 sinalizam aspectos pertinentes ao cargo e(ou) e foi possível questionar sobre a existência de formação continuada para as equipes que atuam nos repositórios. Em cinco (05) repositórios há ações voltadas para desenvolvimento profissional (31,6\%), em três (o3) estão elaborando algum tipo de capacitação (15,8\%), no entanto, em nove (09), não há nada previsto nesse aspecto (52,6\%).

Os respondentes foram questionados quanto ao fato de os respectivos documentos formalizados e(ou) políticas dos repositórios especificarem o público alvo, e a maioria deles contém as informações pertinentes (76,5\%), ficando apenas quatro (o4 ou seja 23,5\%) sem essa indicação.

Com respeito à política do repositório, o questionamento buscou verificar se a instituição torna pública a divulgação os documentos de políticas de acesso, atualizações, preservação e feedback, como também, o termo de depósito e outros documentos, se existentes. De maneira geral, os repositórios possuem ao menos a política de acesso e o termo de depósito, conforme Gráfico 1. Apenas uma (01) universidade indicou possuir a política de acesso, a política de atualização, a política de preservação, a política de feedback e o termo de depósito. Logo, faz-se necessário que as instituições incluam as políticas faltantes no escopo das ações dos repositórios visando regulamentar e conferir maior transparência ao divulgar suas normas de funcionamento.

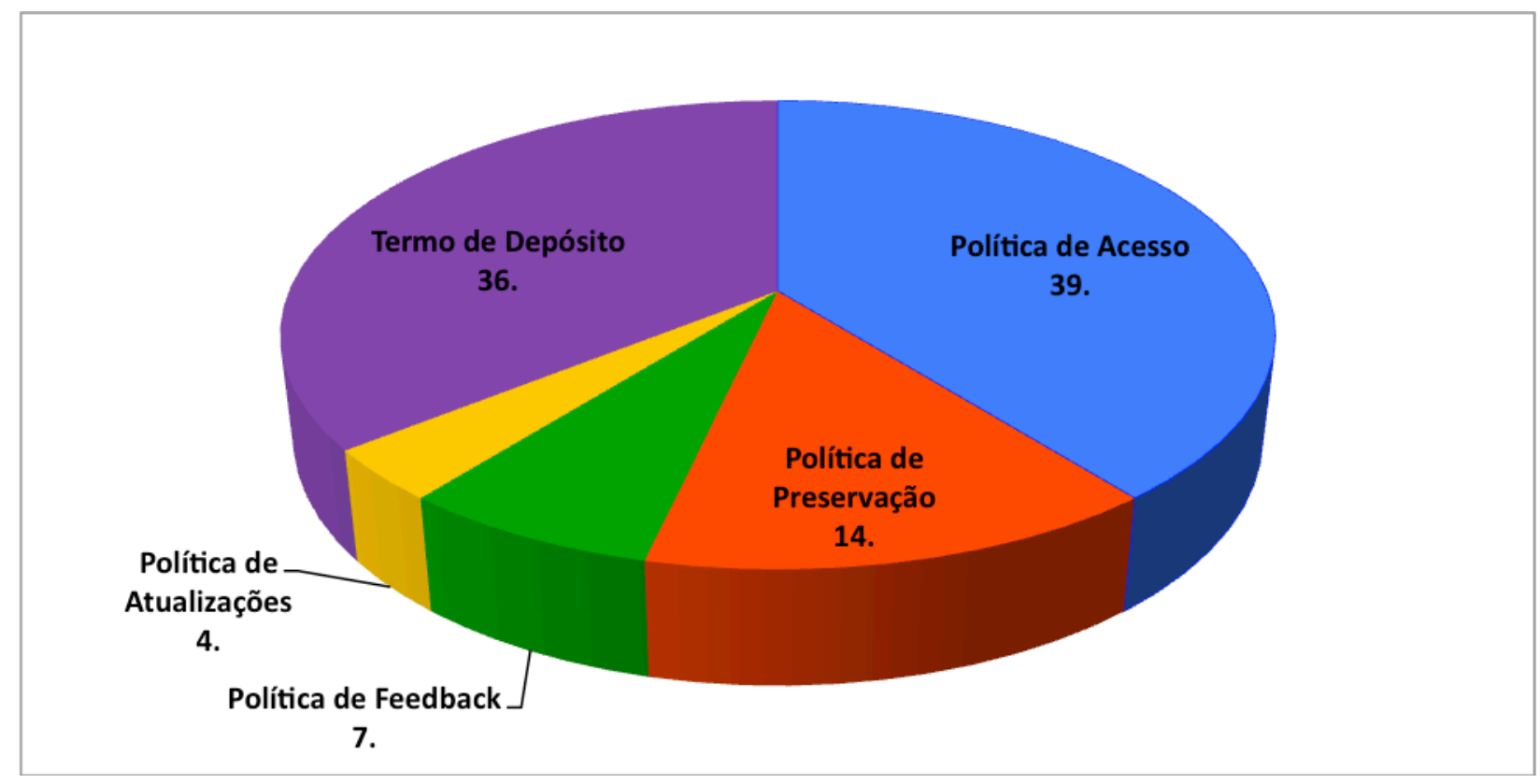

Gráfico 1: Informações sobre as políticas e termo de depósito que os repositórios tornam públicos

Os resultados referentes à próxima questão sinalizaram uma ausência de compromissos (24\%) explicitados em algum documento -, relacionados com os aspectos de transparência, preservação e integridade, visto que os resultados apresentam esse índice de respostas para "Outro/Não opinaram". Por outro lado, obteve-se pelo menos resposta por parte dos respondentes de incidência de um dos compromissos. É possível que essas informações sobre os compromissos estejam presentes nos termos de depósitos ou nas políticas de acesso, conforme apontado na questão anterior em que houve indicativo destes dois documentos como sendo os mais frequentes nos repositórios. 


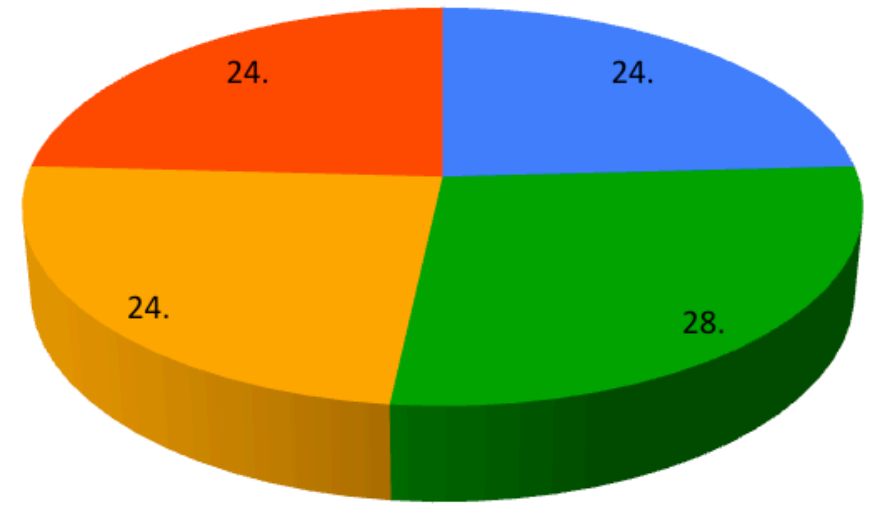

- Compromisso com transparência

- Compromisso com a preservação de seu conteúdo

Compromisso com a integridade

- Outro tipo de compromisso / não opinaram

Gráfico 2: Grau de compromisso dos repositórios com transparência, integridade ou preservação de seu conteúdo

Com respeito ao registro de rotinas que formalizam a atualização e as revisões de conteúdo disponíveis visando acompanhar a evolução tecnológica, os resultados do gráfico 3 apontam para o maior número de respostas negativas (58,8\%). A evolução tecnológica de um repositório é algo contínuo, sobretudo ao considerar questões relacionadas às avaliações ou às auditorias dessas aplicações, além de favorecer à resolução de problemas técnicos. Torna-se necessário adotar práticas de registro documental para os repositórios.

De maneira geral, há ausência de avaliações no tocante ao planejamento das ações dos repositórios. As avaliações, quando ocorrem, costumam ser eventuais e sem periodicidade prevista. Somente $18 \%$ do total afirma realizar avaliações periódicas dentro do prazo previsto.

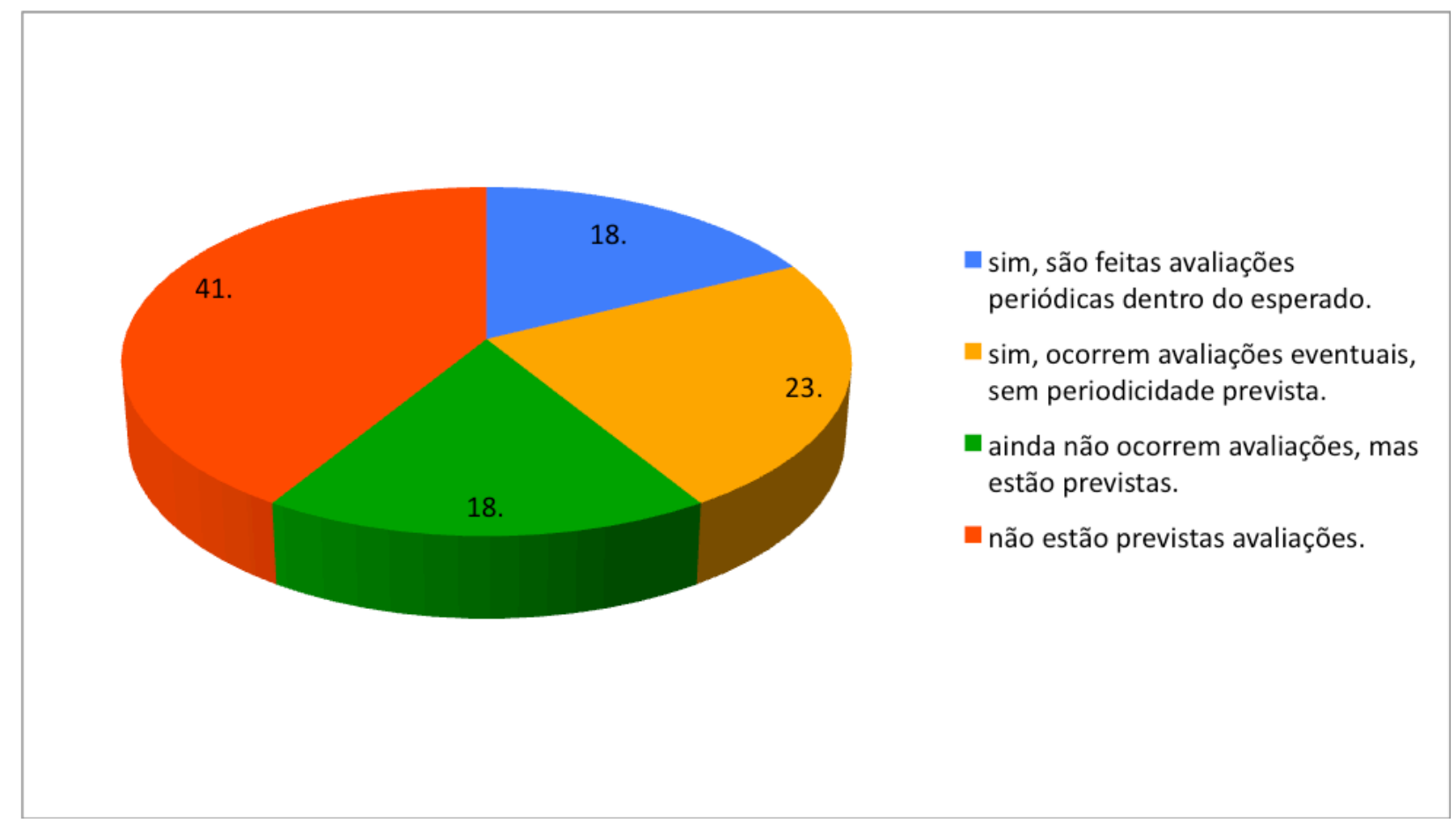

Gráfico 3: Avaliações dos Repositórios. 
Em relação às respostas, do total de repositórios que trabalham com algum modelo de avaliação/ certificação, dois (02) destes afirmaram poder divulgar, porém não enviaram o documento pertinente. E, a equipe de um (01) dos repositórios que afirmou trabalhar com modelo de avaliação/certificação indicou que não poderia enviá-lo pois, todavia, se encontra em fase anterior à implementação. Este cenário demonstra a carência de iniciativas brasileiras unificadas e voltadas para a avaliação de repositórios digitais que verifiquem o aspecto da confiabilidade.

O gráfico 4 a seguir abrange os resultados apontam que a maioria dos repositórios, ou seja, treze deles (76\%) não possuem como prática o planejamento e o controle financeiro. Sabe-se que estes dois itens são indispensáveis para a sustentabilidade dos repositórios. Indica-se, portanto, que as equipes empreendam esforços para a realização dessas atividades.

Uma vez que a maioria dos repositórios não realiza o próprio controle financeiro, consequentemente, não existe transparência em relação à suas práticas financeiras, conforme indicado no gráfico 4 a seguir.

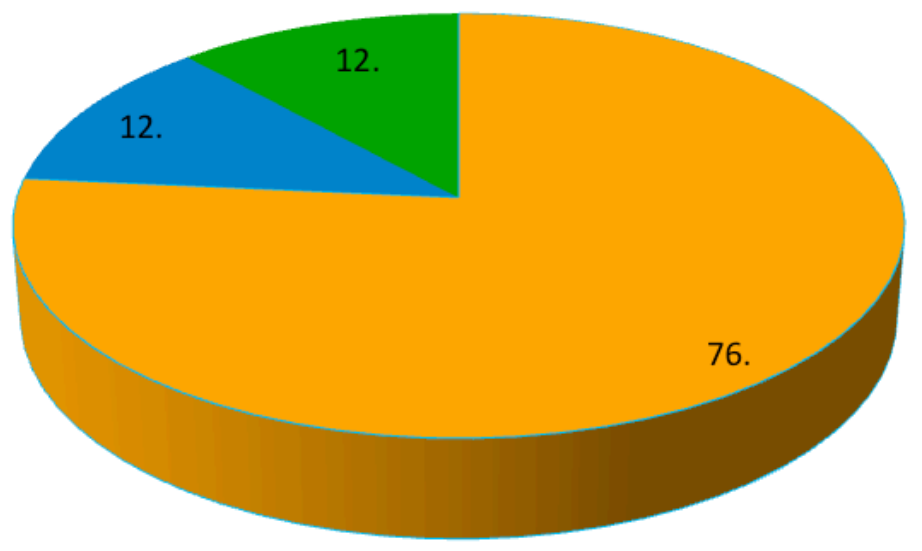

$\square$ Não. 0 repositório não possui documentado e divulga suas práticas financeiras

- Sim. 0 repositório possui documentado e divulga suas práticas financeiras

Outro. Indicar

Gráfico 4: Transparência das práticas financeiras.

Na sequência da investigação, verificou-se que a maioria dos repositórios, isto é treze (13 ou 76\%), afirma não possuir dotação orçamentária específica. Um deles assinalou a alternativa “outros”, porém não indicou a resposta. A ausência de dotação orçamentária específica para o repositório dificulta o planejamento financeiro, e consequentemente, a transparência nos gastos, além da falta de autonomia orçamentária para melhor gerenciamento. Tal problemática se justifica uma vez que, a cada ano os valores destinados às ações podem sofrer variações conforme o contexto e prioridade da instituição. No entanto, destaca-se a importância de recursos destinados exclusivamente para investimentos no repositório institucional e/ou temáticos conferindo maior estabilidade e sustentabilidade financeira.

Quanto aos termos ou declarações de depósitos preenchidos e assinados pelos autores, o gráfico 5 ilustra que os respondentes demonstraram que, na maioria dos casos, tais documentos existem em formato físico e digital, totalizando $53 \%$ da amostra. Em segundo lugar, tem-se que o percentual de $29 \%$ dos repositórios documenta seus termos ou declarações de depósito em formato físico. Visando resguardar os repositórios de questionamentos jurídicos ligados ao direito autoral, é imprescindível ter essa documentação que não 
é nativa digital armazenada em formato físico, para além do digital garantindo a validade legal de tais documentos considerando que os termos digitalizados serão representantes digitais dos originais em formato físico conforme recomendação do $\operatorname{CONARQ}^{8}$ (2010, p.4).

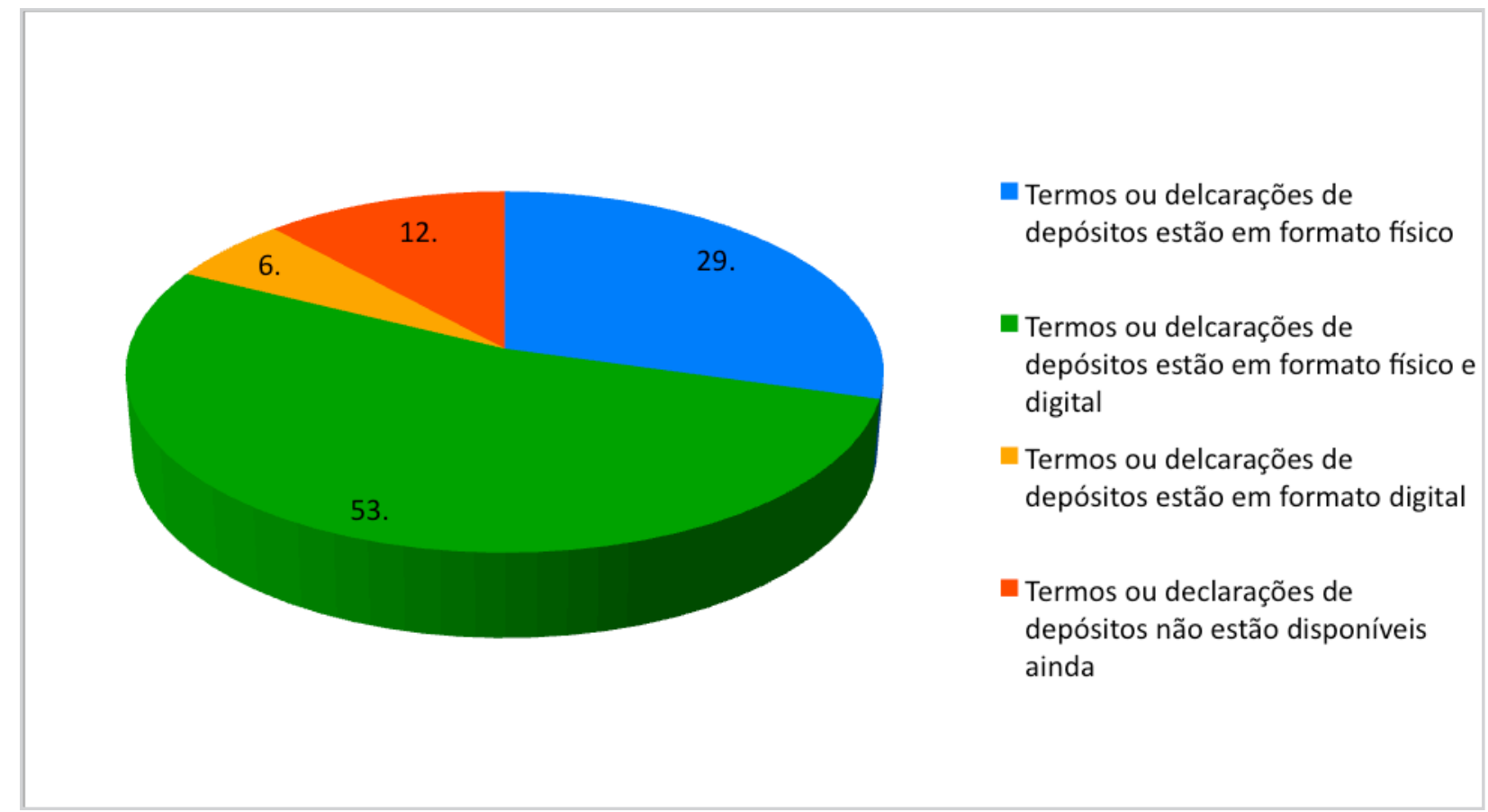

Gráfico 5: Disponibilidade e formatos dos termos ou declarações de depósitos.

A pesquisa também identificou que os direitos autorais e restrições de uso de seu conteúdo estão presentes nos termos ou declarações de depósito em $73 \%$ dos repositórios. Em apenas $27 \%$ dos repositórios, inclui-se o direito de preservação de seu conteúdo nos termos ou declarações de depósitos, logo, pode-se afirmar que, os repositórios brasileiros de maneira geral não estão preparados para serem considerados confiáveis uma vez que a garantia de preservação de seu conteúdo é condição essencial para esta qualidade conferida aos conjuntos de dados.

\section{Discussão}

O estudo possibilitou obter uma análise da situação da amostra de repositórios do país, em que treze (13) já foram implantados integralmente, no entanto, ainda sem contemplar ou atendendo mimimamente aos aspectos de infraestrutura organizacional com base na norma ISO 16363/2012.

Destaca-se, ainda, que apenas três (3) instituições realizam avaliações periódicas em seus repositórios e quatro (4) delas indicaram realizar atividades avaliativas esporádicas, ressaltando-se, contudo, que nenhuma instituição atua com certificação em seus repositórios.

Considerando-se que tanto o processo de planejamento, quanto o avaliativo são de relevância para diagnósticos e prognósticos acerca da implantação, expansão e manutenção de repositórios, entende-se que há necessidade de instituir ações pautadas na norma ISO 16363/2012 com vistas a tornar os repositórios brasileiros confiáveis conforme as recomendações internacionais.

Na literatura, alguns estudos apresentados comprovam tal premissa. O estudo feito por Pavão, Caregnato e Rocha (2016) ${ }^{9}$ analisou quais são os conhecimentos e práticas necessários à equipe responsável pelos repositórios relacionados à preservação digital, e os resultados puderam propiciar uma visão ampliada sobre 
a confiabilidade dos repositórios digitais brasileiros investigados no tocante à um dos pontos abordados pela categoria infraestrutura organizacional da NORMA ISO 16363/2012.

No ano de 2015, Santos e Flores ${ }^{10}$ realizaram um estudo visando fazer uma reflexão sobre os requisitos para se desenvolver um repositório digital confiável. Tal pesquisa apresentou material bibliográfico dos últimos vinte anos, enfatizando os dez mais recentes, concluindo que as ações importantes para que se logre a custódia confiável, dizem respeito: à necessidade de uso de recomendações, diretrizes e(ou) normas; à politica de preservação digital que contemple o aspecto da confiabilidade durante o ciclo documental, e às auditorias para certificação dos repositórios como confiáveis.

Outro estudo realizado em Portugal, publicado por Carvalho ${ }^{11}$, em 2015, descreve o processo de auditoria realizado em vinte e seis repositórios institucionais que fazem parte do projeto Repositório Científico de Acesso Aberto de Portugal (RCAAP) apresentando seus primeiros resultados conforme as recomendações da ISO 16363/2012. Os resultados foram categorizados conforme níveis de maturidade no cumprimento dos requisitos normativos, onde: inexistente (1); incipiente (2); em formação (3); operacional (4); pró ativo (5). Os repositórios receberam classificação em relação ao nível de maturidade para as três dimensões da norma. De maneira geral, no tocante à infraestrutura organizacional, o nível de maturidade dos repositórios foi 2, isto é com nível de maturidade: incipiente.

Os autores supracitados conferem destaque à Trustworthy Repositories Audit and Certification Checklist (TRAC, 2007) ou seja, à ISO 16363/2012 como uma das normas a ser seguida ao se avaliar um repositório digital quanto à sua confiabilidade. Torna-se premissa, portanto, que o repositório alinhado às recomendações desta norma possa ser submetido aos processos de auditoria e certificação, tornando-se um ambiente confiável para a preservação em longo prazo.

Para a efetividade do presente estudo, decidiu-se realizar o levantamento sobre a dimensão da infraestrutura organizacional, da norma ISO16363/2012, com repositórios brasileiros, visto que se trata da base para o funcionamento e posterior desenvolvimento dos mesmos. Pretende-se realizar estudos futuros abrangendo as demais dimensões: gestão de objetos digitais e gestão de segurança, utilizando-se, possivelmente, outros aspectos e (ou) marcos regulatórios. Ademais, visa-se aprofundar conhecimentos referentes à confiabilidade da preservação de acervos digitais.

\section{Conclusão}

A ciência e tecnologia constituem a base propulsora para o desenvolvimento econômico e social de um país. O cenário atual da produção intelectual mudou radicalmente com a chegada e a implementação da Internet, perpassando transversalmente ambientes antes inimagináveis. A amplitude de acesso ao conhecimento científico se deu de forma exponencial, assim como a preocupação referente aos cuidados com sua preservação.

O acesso aberto ao conhecimento científico contribui para o progresso de uma ciência mais eficiente e com menos barreiras, com capacidade de disseminar a produção cientifica dos pesquisadores brasileiros de forma mais rápida. $\mathrm{O}$ aumento de iniciativas de construção de repositórios institucionais no Brasil tem sido bastante significativo nos últimos anos. Com o estudo foi possível viabilizar de forma ampliada o panorama atual das 27 (vinte e sete) instituições que fizeram parte da amostra no universo de 46 repositórios brasileiros com mais de hum mil (1000) registros indexados no Opendoar. Vários problemas de comunicação com as equipes gestoras dos repositórios foram apresentados e no final, dezessete (17) instituições participaram da investigação. Nesse contexto, sentiu-se dificuldade em estabelecer contato com as equipes gestoras dos repositórios brasileiros, de maneira geral, o que pode sinalizar atividade laboral em excesso, no entanto, reforça-se a relevância de os gestores colaborarem com os pesquisadores para que se possa associar um compromisso de melhorias teórico-sistêmicas para os repositórios do país. Por outro lado, entende-se a 
necessidade de as instituições detentoras de repositórios, mediante a alta gestão respectiva, apoiarem e viabilizarem ações que impulsionem estas ferramentas visto que são essenciais para a divulgação de sua própria produção intelectual. Em escopo nacional, a falta de uma política de acesso aberto também implica no desconhecimento da real função de um repositório institucional. Abarcando todas as instâncias de atuação, é possível empreender melhorias significativas para a nossa grande rede de repositórios no país por meio de processos avaliativos abrangentes seguindo-se como base a presente investigação.

\section{Referências}

1. CROWN R. The case for institutional repositories: a SPARC position paper. ARL Bimonthly Report. 2002 Aug; 223. p.1-4. Disponível em: https://ils.unc.edu/courses/2015 fall/inls700 001/Readings/Crow2002CaseforInstitutionalRepositoriesSPARCPaper.pdf

2. COSTA SMS, LEITE FCL. Insumos conceituais e práticos para iniciativas de repositórios institucionais de acesso aberto à informação científica em bibliotecas de pesquisa. In: Sayão, LF. et al. Implantação e gestão de repositórios institucionais: políticas, memória, livre acesso e preservação. Salvador: EDUFBA; 2010. p.163-202.

3. LYNCH CA. Institutional repositories: essential infrastructure for scholarship in the digital age. ARL Bimonthly Report. 2003 Feb; 226.p.1-7. Disponível em: https://www.cni.org/wp-content/ uploads/2003/02/arl-br-226-Lynch-IRs-2003.pdf

4. Conselho Nacional de Arquivos. Diretrizes para a implementação de repositórios arquivísticos digitais confiáveis. Rio de Janeiro: Conarq; 2015. Disponível em: http://www.conarq.arquivonacional.gov.br/ images/publicacoes textos/diretrizes rdc arq.pdf

5. Instituto Brasileiro de Informação em Ciência, Tecnologia e Inovação [Internet]. Sobre repositórios digitais. Disponível em: http://www.ibict.br

6. Organização Internacional de Normalização ISO 16363/2012. Space data and information transfer systems: Audit and certification of trustworhy digital repositories. Genebra: ISO; 2012.

7. OPENDOAR Diretório de Repositórios de Acesso Aberto [Internet]. Search or browse for repositories. Disponível em: http://www.opendoar.org

8. Conselho Nacional de Arquivos. Recomendações para Digitalização de Documentos Arquivísticos Permanentes Rio de Janeiro: Conarq; 2010. Disponível: http://www.conarq.arquivonacional.gov.br/ images/publicacoes textos/Recomendacoes digitalizacao completa.pdf

9. PAVÃO CMG, CAREGNATO SE, ROCHA, RP. Implementação da preservação digital em repositórios: conhecimento e práticas. Revista Digital de Biblioteconomia e Ciência da Informação. 2016 Set./dez; 14 (3):407-425.

10. SANTOS HM, FLORES D. Repositórios digitais confiáveis para documentos arquivísticos: ponderações sobre a preservação em longo prazo. Perspectivas em Ciência da Informação. 2015; 20( 2):198-218.

11. CARVALHO J. Auditoria ISO 16363 a repositórios institucionais. In: Actas do Congresso Nacional de Bibliotecários, Arquivistas e Documentalistas. Évora: Associação Portuguesa de Bibliotecários, Arquivistas e Documentalistas; 2015. 